\title{
Laboratory Development of a Passive Proportional Sampler for Overland Flow Studies in Agricultural Fields
}

\author{
T. Declan Ryan and Dermot Forristal \\ ${ }^{l}$ CELUP (Crops, Environment and Land Use Programme), Teagasc, Carlow, Ireland \\ Email:declan.ryan@teagasc.ie \\ http://dx.doi.org/10.7451/CBE.2014.56.1.1 \\ Received: 2014 October 11, Accepted: 2014 November 20, Published: 2015 February 6
}

Ryan, T.D. and D. Forristal. 2014. Laboratory development of a passive proportional sampler for overland flow studies in agricultural fields. Canadian Biosystems Engineering/Le génie des biosystèmes au Canada 56: 1.1-1.7. Water-quality in many rivers remains poor and needs to be improved. Diffuse pollution continues to cause difficulties. Some instruments are available which can monitor pollution of rivers from land. They allow measurement and sampling of overland flow (OLF), but they do not offer the precision required (proportional sampling and samples $0.1 \%$ of OLF). A laboratory unit was constructed to mimic instrument performance in the field. This was used to test three sampler designs. A V-notch weir was used in the first sampler and a Sutro weir in the second and third as this unit possessed a proportional discharge to head ratio, which the Vnotch weir did not have. Other parameters investigated included ground slope, sampler slope, pipe size and port location. The remaining issues of nozzle size $(0.7,1.0$ and $2.0 \mathrm{~mm})$, the number of $1.0 \mathrm{~mm}$ nozzles and the effect of aspiration were investigated. The arrangement with the Sutro weir and three 1.0 $\mathrm{mm}$ nozzles in series gave proportional discharge and the target low sampling rate of $0.1 \%$. This will allow the calculation of sediment and chemical losses for the monitored area and will put the loss in context with other losses in a catchment. Keywords. Nozzle, overland flow, proportional sampling, sampler La qualité de l'eau est médiocre dans beaucoup de rivières et doit être améliorée. La pollution diffuse continue de poser problème. Certains instruments sont disponibles pour contrôler la pollution des cours d'eau provenant des terres. Ils permettent de mesurer et échantillonner les eaux de ruissellement, mais n'offrent pas la précision requise (prélèvement proportionnel et échantillons à une précision de $0,1 \%$ ). Un appareil de laboratoire a donc été construit pour imiter la performance d'instruments sur le terrain. Cet appareil a été utilisé pour examiné trois échantillonneurs. Un déversoir à entaille en $\mathrm{V}$ a été utilisé pour le premier échantillonneur mais le déversoir Sutro a été utilisé pour le deuxième et troisième parce que le déversoir Sutro possédait un débit proportionnel au rapport de pression ce que le déversoir à entaille en V n'a pas. D'autres paramètres ont été examiné ; dont la pente du terrain, la pente de l'échantillonneur, le diamètre des tuyaux et l'emplacement des ports. Les questions concernant la taille de la buse $(0,7,1,0$ et 2,0 mm), le nombre de buses de 1,0 $\mathrm{mm}$ et l'effet d'aspiration ont été étudiées. En disposant le déversoir Sutro, avec trois buses de 1,0 $\mathrm{mm}$ en série, on obtient un flux proportionnel et on obtient aussi l'objectif d'une plus faible fréquence d'échantillonnage de $0,1 \%$. Cela permettra le calcul de la quantité en sédiments et en produites chimiques pour la zone surveillée, en mettant la perte en contexte avec d'autres pertes dans un bassin versant. Mots clés: la buse, les eaux de ruissellement, l'échantillonnage proportionnel, l'échantillonneur.

\section{INTRODUCTION}

The use of fixed installations to measure OLF on farmland is not always sufficient to deal with the problem of diffuse pollution. This type of pollution is highly variable and must be measured in a wide range of situations. Therefore small stand-alone monitors are required that can be placed anywhere at low cost. They must operate singly or in groups and give information, which is, similar to that offered by fixed monitors, albeit without so much detail. This approach is required anywhere a significant proportion of river channel is polluted primarily from diffuse sources. These sources include farm slurry spread on poorly drained land in January to March each year (DAFF 2010).

Water body protection needs to be approached from a catchment perspective and any one catchment may require many improvements to reduce nutrient losses (Clothier et al. 2011). These may include alterations to streams, farm management and wastewater treatment as found in the UK (Cooksley et al. 2011). Part of the change required in farm management is reducing nutrient loss from vulnerable fields, where free draining soils give rise to leaching and poorly drained soils cause export of $\mathrm{P}$ and other pollutants to surface and groundwater. Therefore, it is important that fields prone to nutrient loss be identified so that corrective measures may be applied.

In catchment research it is difficult to determine the hydrological status of farms and fields due to mixing of pollution from different sources in a river. Methods are available to determine the hydrological status of small areas, but the methods are not applicable to every situation. In some countries, more complete hydrological information is available which help indicate the nutrient loss risk. For example, the HOST (Hydrology of Soil Types) system in the UK describes the hydrology of every soil and is available throughout the country. It can apply at any scale and indicates readily whether soils have good or poor drainage (Marechal and Holman 2005). This system is not available in many countries so some other method must be found to identify wetland prone to pollution by OLF.

There is a range of instruments available to monitor OLF. Many of these are expensive to use or fixed to one position. Some are low cost and mobile (Harmel et al. 
2006). A number of devices developed in the USA measure and/or sample OLF, but only three of these provide a sample. The Percent Discharge Meter, which consists of a rectangular flat plate with lines of 10 divisions in two successive groups, takes a $10 \%$ sample and a $1 \%$ sample (Franklin et al. 2001). Malone et al. (2003) describe a drop former and rotating slot sampler for low discharges, between 0.5 and $200 \mathrm{~mL} \mathrm{~min}^{-1}$. The sampler of Bonta and Goyal (2000) uses a drip former over a bucket wheel.

These compact mobile samplers are designed to allow many sites or large areas to be investigated at once and allow statistical analysis of the resulting data. Any other data that is related to OLF could be recorded and collated with the OLF data.

Existing samplers did not satisfy our objectives. Tests indicated the design of Franklin et al. (2001) was not sufficiently precise. The sampler by Malone et al. (2003) was not sufficiently robust for fieldwork, and the design of Bonta and Goyal (2000) was more complex than required for a sampler. Based on the need for improved sampling suitable for research needs, the object of the project was to:

(a) develop a sampler which was inexpensive and portable,

(b) collect samples and record total discharge, and

(c) provide sampling proportional to discharge and sample volume of approximately $0.1 \%$ of discharge.

\section{Design criteria}

MATERIALS AND METHODS

The design criteria in this project were that the sampler would take a sample proportional to discharge and that it should be approximately $0.1 \%$ of discharge volume.

\section{Design options}

The instrument under investigation is an aluminum $\mathrm{V}$ shaped dam with walls $2 \mathrm{~m}$ wide and approximately 0.15 $\mathrm{m}$ high. In the middle of the weir a V is located to control discharge through the unit. A sampler tube with or without nozzles is connected to the wall near the weir and is further connected to a sample bottle nearby.

\section{Test apparatus}

The OLF indicator test apparatus (OFI unit) was constructed in a laboratory (Fig. 1). This consisted of a triangular shallow tank $(1.65 \mathrm{~m}$ wide and $1.2 \mathrm{~m}$ from front to back) and mounted on concrete blocks with an outlet at the lowest corner. It was constructed from a waterproof plywood base and aluminum sides $0.15 \mathrm{~m}$ high. The tank could be set at an angle, variable from 0 to $15^{\circ}$ towards the outlet to mimic field slopes. Water supply to the OFI unit was from an overhead tank, which was connected to a diffuse outlet at the back of the unit supplying water across the full width. The water exited the OFI tank through a discharge control device or weir. Two weirs were evaluated: a V-shaped weir and a Sutro weir (ILRI: 1978). The V-shaped weir was cut at a corner of a small frame (Sampler 1). Head levels within the rig were monitored

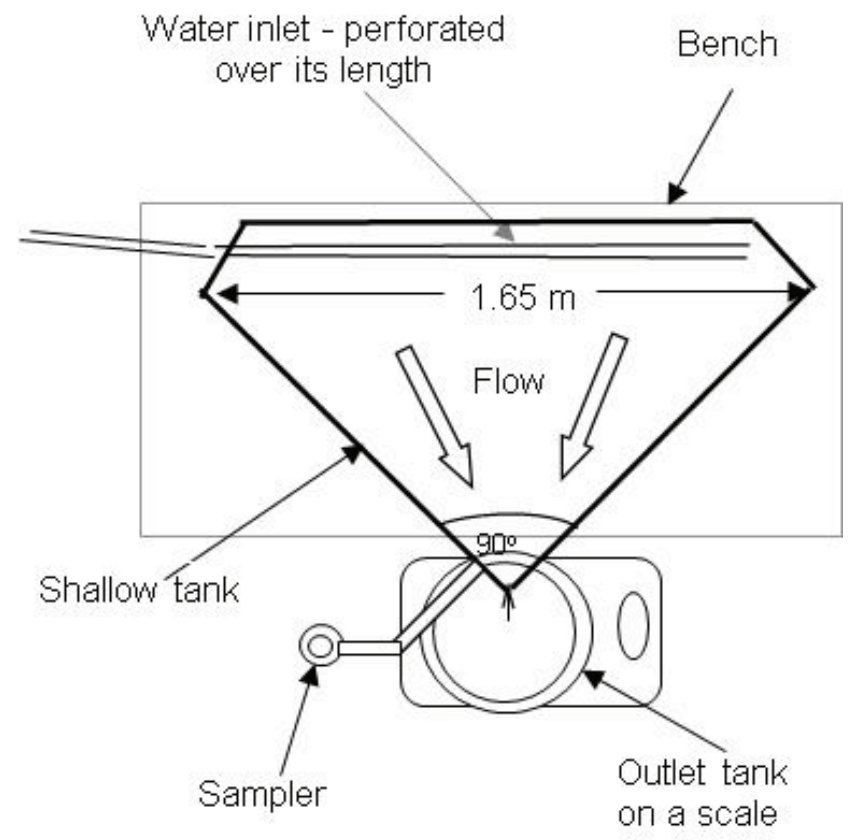

Fig. 1. Plan view of the sampler experimental rig (Samplers 1-3).

using a ruler and spirit level working from a fixed point. The evaluated samplers all took samples through the aluminum wall close to the weir. Samples were collected in a one-liter bottle, giving a volumetric record with Sampler 1. For Samplers 2 and 3, the sample was weighed (capacity $3100 \mathrm{~g}$ and precision $0.1 \mathrm{~g}$ ). Discharge through the weir of the OFI Unit was recorded using a 100-liter tank mounted on a weighing scale (capacity $150 \mathrm{~kg}$ and precision $0.02 \mathrm{~kg}$ ) before discharge to waste.

Approximately 80 tests were performed so it is not possible to present all this information here. Therefore to facilitate reporting, three sampler designs were identified (Table 1 and Fig. 2). These are discussed below.

Sampler 1 is simply a plastic pipe with rubber tube connections attached to the tank wall and to the sampler bottle. The latter has volume markings to indicate sample volume. The V-shaped weir was used. The test details are summarized in Table 1. Four plastic pipes (3, 4.2, 5.25, 5.5 $\mathrm{mm}$ I. D.) connecting the sample bottle to the test apparatus and two plastic restrictor nozzles $(1.0,0.7 \mathrm{~mm}$ I.D.) at the connection point of the tube to the test apparatus wall were used with this sampler. Other parameters were tested using the $3 \mathrm{~mm}$ ID tube in the sampler. These included sampler pipe slope, sampler outlet position, discharge rate and tank slope.

Sampler 2 used the Sutro weir and three nozzles, one of which was a $2 \mathrm{~mm}$ ID X 10mm segment of plastic pipe and the others were nozzles of $1 \mathrm{~mm}$ and $0.7 \mathrm{~mm}$ ID. In this sampler for successive tests the restricting nozzle was mounted in the upright of an inverted T-piece of $9 \mathrm{~mm}$ ID tube, shortened to suit water level and placed on the floor of the tank. For accurate sampling, discharge to the 


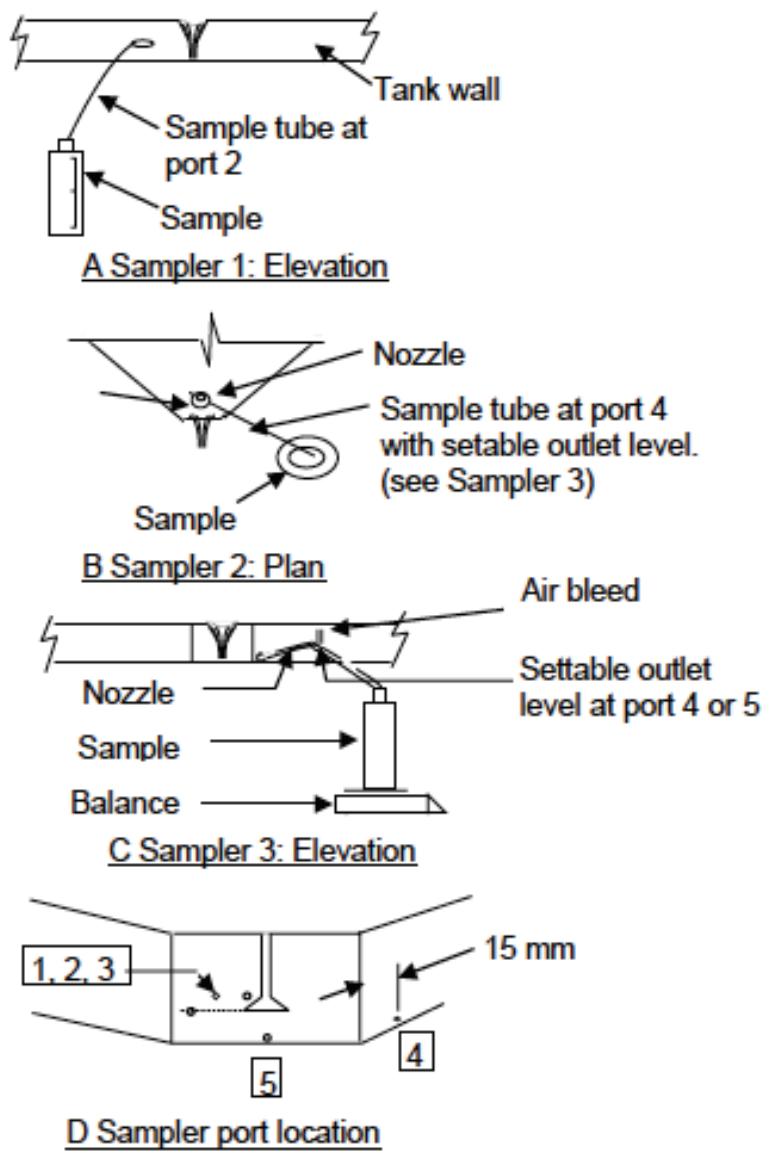

Fig. 2. Diagrams of three samplers used in the trials.

sampler should start and finish at the same time as OLF. To this end a high point in the sample tube was set at the base level of the weir to control start and stop time for discharge to the sampler.

Sampler 3 had an air bleed in the sampling line to reduce suction in the pipe to the sample bottle (Fig. 2). In some tests this vent was blocked. One, two or three nozzles $(1.0 \mathrm{~mm}$ ID) were used in the sampler. One was placed in a T-piece on the tank floor, a second was placed at the inlet end of the T-piece for aspiration and the third nozzle was at the outlet end of that T-piece. This last nozzle discharged to air through a meniscus creating additional resistance to discharge. The other two nozzles were drowned throughout sampling and no meniscus was created there.

It was difficult to match OLF data from the field to the laboratory unit due to very high maximum OLF over short periods and much lower average OLF over longer periods. Nevertheless data representative of OLF were sought from a 0.46 ha and a 1.45 ha grassland site for the winter period 2003/2004 at a neighboring research center and at a 1.0 ha site under tillage at our own center for the winter period 2006/2007. Automatic flow meter sampler recorded these data. Maximum and Quartile rates of OLF were calculated from actual rates of discharge. Maximum rates for the three sites were $16.4,9.86$, and $2.8 \mathrm{~L} \cdot \mathrm{min}^{-1}$
Table 1. Test parameters and values used with the OFI laboratory rig.

\begin{tabular}{|c|c|c|}
\hline & Test Parameters $^{[1,2]}$ & $\begin{array}{l}\text { Test Values } \\
\text { (unless stated otherwise ) }\end{array}$ \\
\hline \multirow[t]{7}{*}{ Sampler 1} & Pipe dia. & Weir type; V-weir \\
\hline & Sampling Ratio & $\begin{array}{l}\text { Sample tube; } 3 \mathrm{~mm} \text { ID } \\
\text { plastic }\end{array}$ \\
\hline & Sampler slope & Nozzle dia.; $0.7,1.0 \mathrm{~mm}$ \\
\hline & Sampler position & Sample tube slope; $21 \%$ \\
\hline & Water discharge rate & Port position; 2 \\
\hline & Tank slope & Inlet flow: 15L. $\mathrm{min}^{-1}$ \\
\hline & Sampling ratio & \\
\hline \multirow[t]{5}{*}{ Sampler 2} & Water discharge rate & Weir type; Sutro weir \\
\hline & Sampling ratio & $\begin{array}{l}\text { Sample tube; } 10 \mathrm{~mm} \text { ID } \\
\text { rubber }\end{array}$ \\
\hline & $\mathrm{P} / \mathrm{V}$ characteristic & $\begin{array}{l}\text { Nozzle dia.; } 0.7,1.0,2.0 \\
\text { mm } \\
\text { Sample tube slope; N.A. }\end{array}$ \\
\hline & & Port position; 4 \\
\hline & & Inlet flow: 15 L. $\mathrm{min}^{-1}$ \\
\hline \multirow[t]{6}{*}{ Sampler 3} & $\mathrm{P} / \mathrm{V}$ characteristic & Weir type; Sutro weir \\
\hline & Start/Stop & $\begin{array}{l}\text { Sample tube; } 10 \mathrm{~mm} \text { ID } \\
\text { rubber }\end{array}$ \\
\hline & Water discharge rate & Nozzle dia.; $1.0 \mathrm{~mm}$ \\
\hline & Nozzles in the sampler & Sample tube slope; N.A. \\
\hline & Air bleed & Port positions; 4 and 5 \\
\hline & Sampling ratio precision & Inlet flow: 15 L.min ${ }^{-1}$ \\
\hline
\end{tabular}

[1] Some or all of the test parameters attributed to Sampler 1 were used with Sampler 1 in each test. Likewise some or all test values for Sampler 1 were used with Sampler 1. The same applies for Samplers 2 and 3.

[2] Tank slope was $3.5 \%$ in all the tests above.

and the lowest Quartile at the 0.46 ha site was $0.03 \mathrm{~L} \cdot \mathrm{min}^{-1}$ to yield the following test data $(0.42,1.0,6.0$ and 15.0 L. $\left.\min ^{-1}\right)$. While the highest value used is close to the highest rate of discharge recorded the lowest rate used was not as low as the first Quartile of field data but it was the lowest rate the laboratory equipment could achieve with ease. The other two test data values were chosen empirically to fit between the maximum and minimum values. This gave a spread of values in the analysis, which made the calculations more meaningful. There is little doubt that these instruments will encounter discharge of $1.0,6.0 \mathrm{~L} \cdot \mathrm{min}^{-1}$ or close to these values in the field.

\section{RESULTS AND DISCUSSION}

The results presented below indicate the volume of the sample and uniformity of sampling under a typical range of discharge conditions. The sampler designs are novel and do not appear in the literature. They are constructed from inexpensive plastic and rubber components and being light and of simple construction they are easily portable. Setting up the OFI can be a little difficult however due to the need to have the sampler and weir base on the same level. 


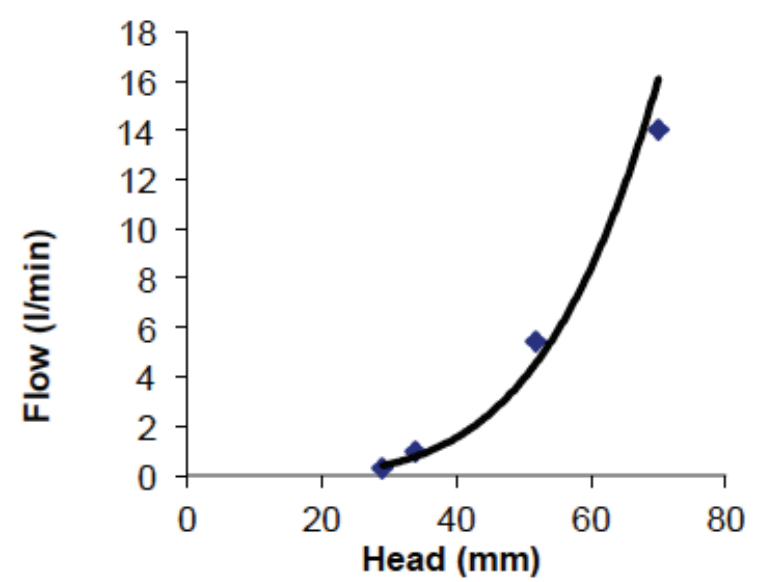

Fig. 3.1. Characteristic curve for a V-notch weir ( $R 2=0.99)$

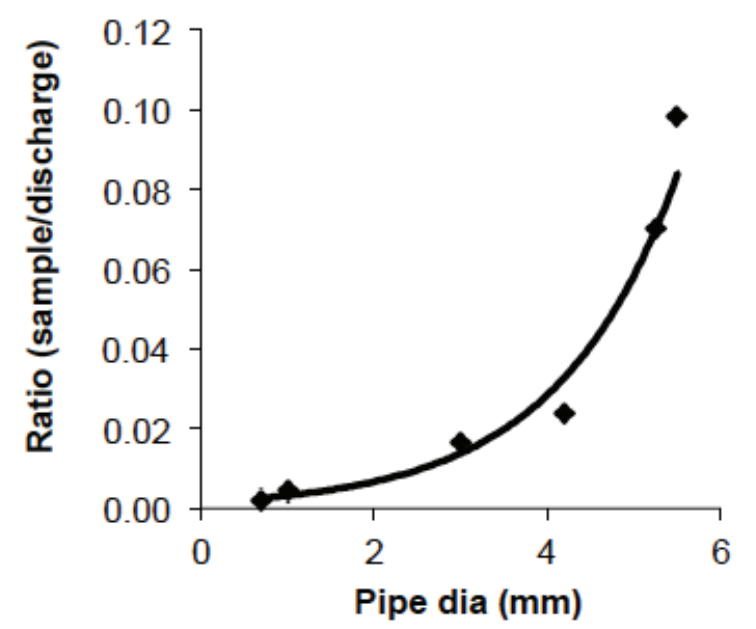

Fig. 3.3. Effect of pipe size

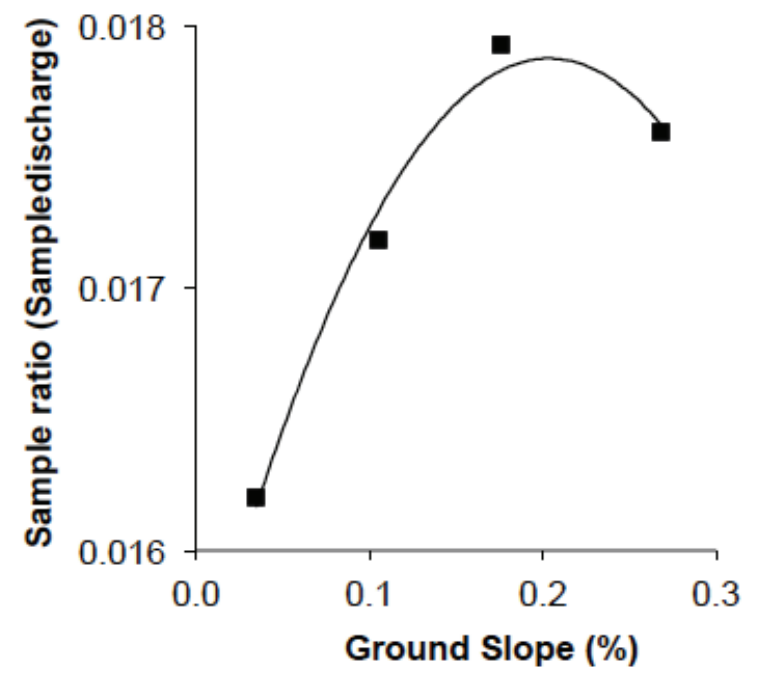

Fig. 3.5. Effect of ground slope on sample rate ( $R 2=0.98)$

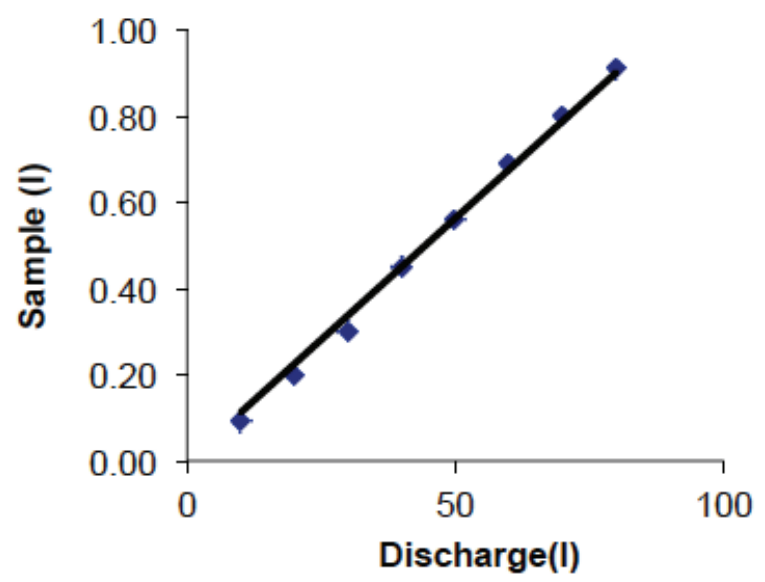

Fig. 3.2. Sample volume plotted against flow $(\mathrm{R} 2=0.99) 3 \mathrm{~mm}$ pipe.

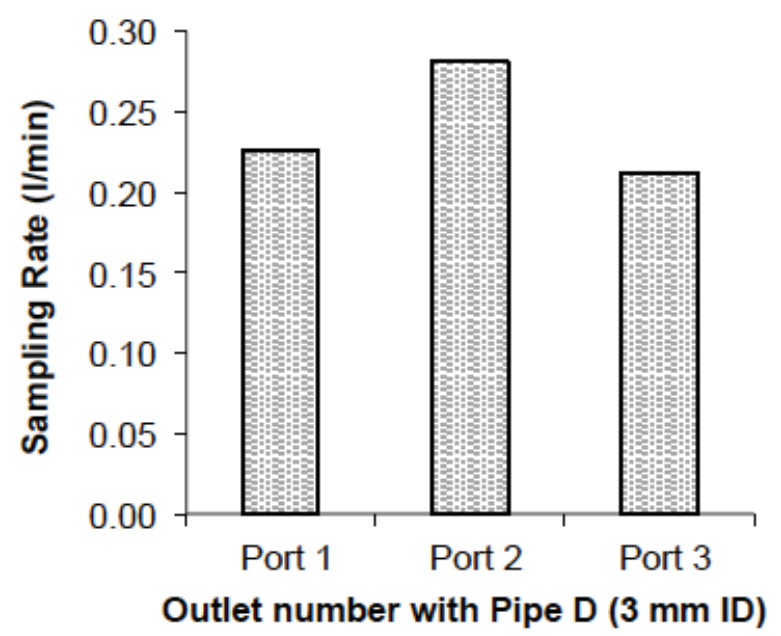

Fig. 3.4. Effect of port number on sampling rate

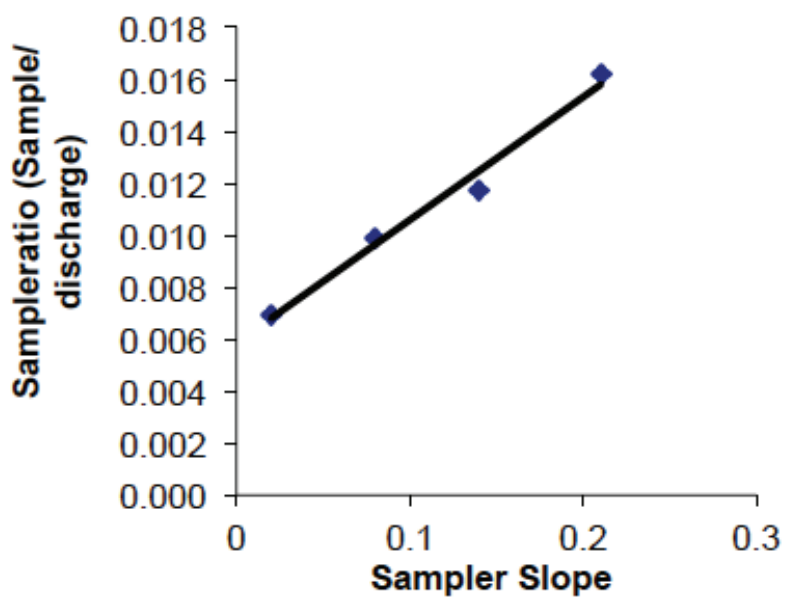

Fig. 3.6. Effect of sampler slope

Fig 3. Measurements with the V-notch weir (Sampler 1) 
Table 2. Analysis of variance for key design parameters of the proportional samplers.

\begin{tabular}{llccccc}
\hline Parameter & Source & $\mathrm{N}^{[1]}$ & $\mathrm{F}^{\text {crit }}$ & $\mathrm{F}$ & P-value $^{[2]}$ & Signific[3] \\
\hline Sutro straight/curve & Fig. 4 & 31 & 4.00 & 9.84 & 0.0026 & $\mathrm{~S} * *$ \\
Nozzle size & Fig. 5 & 2 & 19.0 & 887 & 0.0011 & $\mathrm{~S} * * *$ \\
Number of nozzles & Fig. 6 & 3 & 6.94 & 45.5 & 0.0018 & $\mathrm{~S} * *$ \\
Start/stop: nozzle in air/water & Table 3 & 4 & 5.98 & 30.1 & 0.0015 & $\mathrm{~S} * *$ \\
Aspiration/Not & Fig. 7 & 3 & 18.5 & 19.7 & 0.0472 & $\mathrm{~S}$ \\
\hline
\end{tabular}

[1] Number of values, [2] Probability,.[3]Significance: *,** and *** indicates degree of significance.

Measurements with the V-notch weir are summarized in Figs. 3.1 to 3.6. The discharge through the V-notch weir has a curvilinear relationship with head (Fig. 3.1). This is typical of this type of weir as the discharge equation shows head to be raised to the power of 2.5 (ILRI 1978), far above the value of 1 to be expected with a proportional weir. Discharge through Sampler 1 and the weir are proportional showing it is possible to get a proportional sample with the V-notch weir (Fig. 3.2).

For the same sampler, sample ratio (sample volume /discharge volume) is plotted against pipe diameter using pipe sizes from 0.7 to $5.5 \mathrm{~mm}$ ID to give a curvilinear relationship. Sample ratio increases with pipe size (Fig. 3.3). The effect of port position in the test apparatus (Fig. 2) on sampling rate (sample volume over time) is shown in Fig. 3.4. This suggests that port location can have an effect on sampling rate and port 2 gave the highest discharge due to its position closest to the weir. In the graph the difference between highest and lowest is of the order of $20 \%$. This could be useful in setting sample size.

The effect of ground slope on discharge rate through the weir is illustrated (Fig. 3.5). The graph shows some scatter but a good regression value. It indicates a range of values that is approximately $10 \%$ of the mean. This could be important in field trials where slope varies from one site to the other and the ratio of sample to discharge volume will not be constant. It is to be expected that slope of the sampling pipe from the tank to the sample bottle will affect sample volume (Fig. 3.6). The sampling ratio (ratio of sample size to corresponding discharge volume) increases steadily with sampler slope so in the field efforts are made to eliminate variations in slope of the sampler pipe. Sampler 1 indicated the parameters, which should be chosen for the other two samplers.

As the V-notch weir did not have a proportional characteristic curve the Sutro weir, which has a proportional characteristic curve ILRI (1978) was used instead for final measurements.
Equations are given to define the shape of the weir and the discharge from it (ILRI 1978). Discharge from the weir is proportional to water head with the exception of very low heads where the relationship is curved (Fig.4). It is not unusual for discharge measurement structures to have low discharges that deviate from other flows. In this trial, discharge through the Sutro weir was measured 43 times so any non-linearity in discharge was clearly evident (Table 2). These measurements indicated that discharge at head below $8 \mathrm{~mm}$ should be discounted and ILRI (1978) suggested a similar cut-off. This applies to most weirs but where the discharge through a weir is measured the measurements below $8 \mathrm{~mm}$ are true.

Graphs of discharge against head are plotted for the Sutro weir with different sized nozzles (Fig. 5, Table 1: Sampler 2). The data fit well with $\mathrm{R}^{2}$ values of $0.83,0.92$ and 0.88 for nozzles of $0.7,1.0$ and $2.0 \mathrm{~mm}$ respectively (Fig. 5). Of course the discharge through the $2 \mathrm{~mm}$ tube nozzle is very much larger than that through the smaller nozzles.

Sample volume is directly proportional to discharge through the weir in Fig. 6. All three nozzles affected discharge and the effect is proportional and significant (Table 2). The sampling rate is evident from these lines with 1,2 and 3 nozzles taking a sample ratio of 0.0024 , 0.0018 and 0.0011 respectively. These values are consistent over the range described in the graph. The lowest value will collect a sample of less than $1.0 \mathrm{~L}$ in a typical OLF event. However with extreme events sample volumes could be larger so a larger receptacle may be required. Sampler 2 revealed the sample size available with each nozzle.

Sampler 3 works well over the operating range of the equipment. With three $1 \mathrm{~mm}$ nozzles in series installed in the sampler, a discharge as low as $0.8 \mathrm{~L}^{\mathrm{min}} \mathrm{min}^{-1}$ can be sampled. Between this lower limit and the upper value for the trial of $14 \mathrm{~L} . \mathrm{min}^{-1}$ Sampler 3 sampled the discharge. The value of $14 \mathrm{~L} . \mathrm{min}^{-1}$ is close to the upper limit of

Table 3. Start and stop times for the proportional sampler (Sampler 3) with nozzles in air or in water.

\begin{tabular}{lccccccccc}
\hline Sample & \multicolumn{9}{c}{ Nozzle in air } \\
\hline Start & 153 & 155 & 149 & 149 & 139 & 139 & 139 & 139 & 145.25 \\
Stop & 143 & 146 & 140 & 140 & 137 & 140 & 140 & 140 & 140.75 \\
Difference & 10 & 9 & 9 & 9 & 2 & 1 & 1 & 1 & 5.25 \\
Average & & 9.25 & & & & 1.25 & & \\
\hline
\end{tabular}




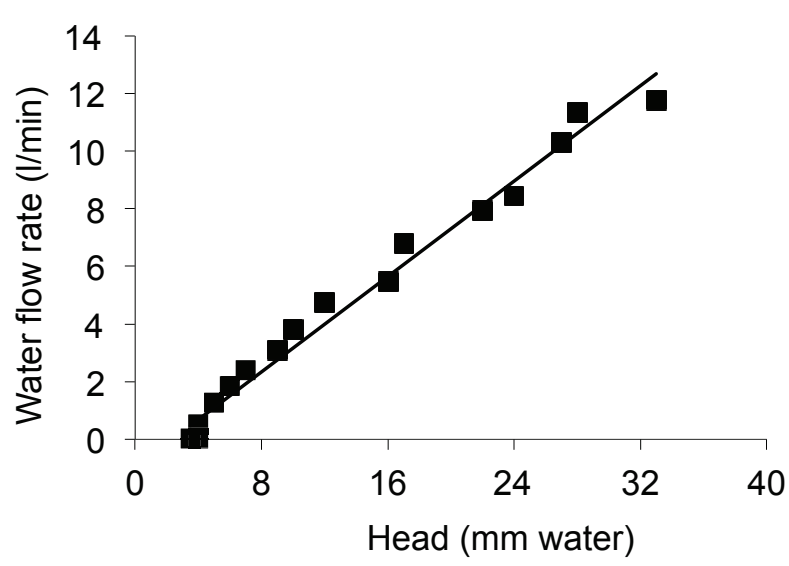

Fig. 4. Head/volume flow curve for the Sutro weir $\left(R^{2}=\right.$ 0.98) (Sampler 2)

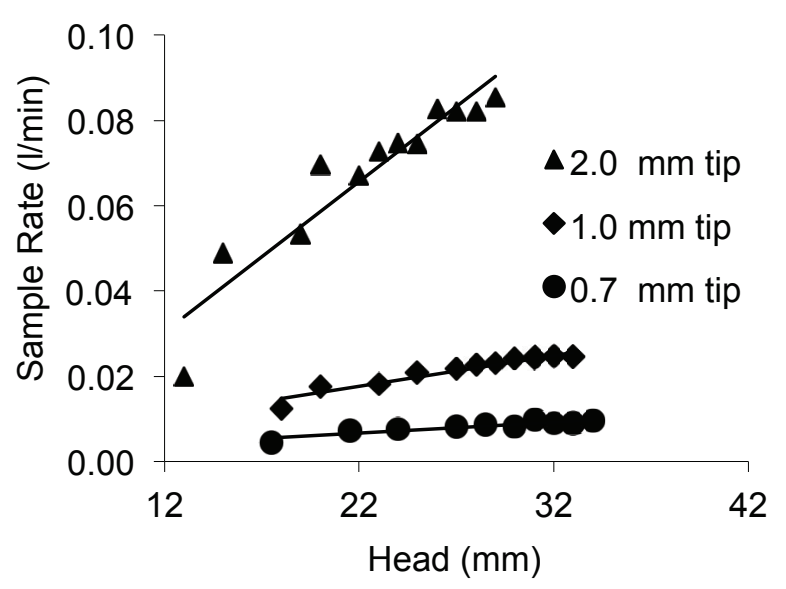

Fig. 5. Sample rate vs. head using nozzles $0.7,1.0$ and $2.0 \mathrm{~mm}$ with $R^{2}$ values of $0.83,0.92$ and 0.88 respectively (Sampler 3).

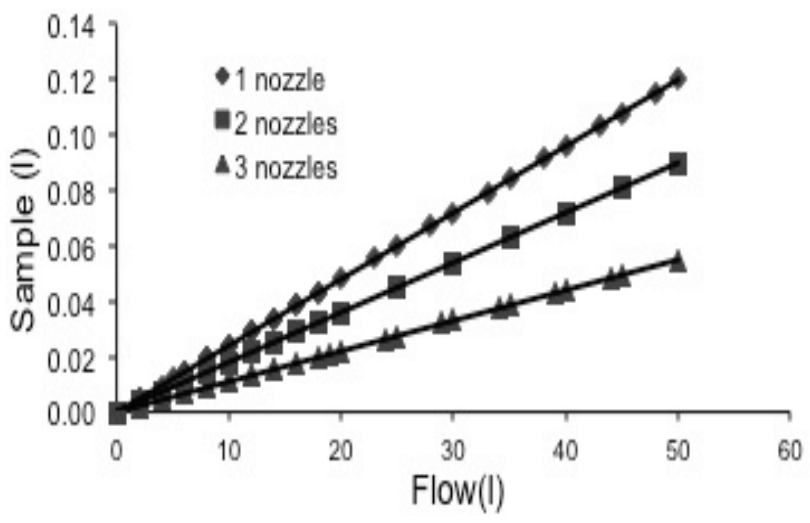

Fig. 6. Regression lines for sample mass plotted against discharge for 1,2 or 3 nozzles of $1.0 \mathrm{~mm}$ diameter and 1 bend in the sampler. R-squared values are $0.99,0.89$ and 0.99 with respect to nozzles. (Sampler 3).

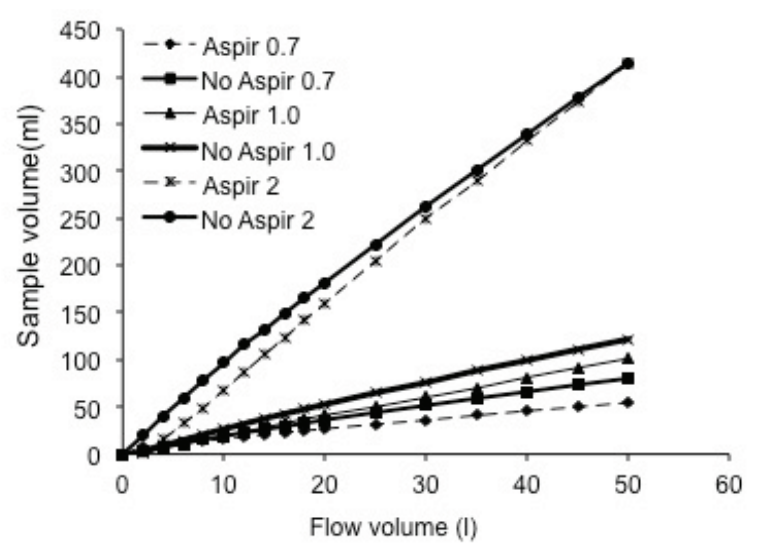

Fig. 7. Effect of aspiration on sample volume for nozzles in Sampler 3: $0.7 \mathrm{~mm}, 1.0 \mathrm{~mm}$ and $2 \mathrm{~mm}$.

discharge from a $2 \mathrm{~m}$ wide strip sampled by the field instrument, 16.1 L.min ${ }^{-1}$. This is the maximum discharge per $\min$ at the 0.46 ha site where the highest daily discharge rate of the three sites above was recorded.

Table 3 shows the start and stop times for Sampler 3. Many of the data were recorded using nozzles discharging to air. These had a meniscus that offered resistance to discharge and moderate differences between start and stop times were recorded. The remaining data were from samplers with submerged nozzles where no meniscus occurred and start and stop times were closer together. The difference due to meniscus was significant (Table 2). For accurate sampling, head across the sampler should be close to zero at the beginning and end. Nozzles should be submerged when the main discharge starts and stops.

Data with and without aspiration are given in Fig. 7. The sampler with the sealed vent provided $15 \%$ more sample than the aspirated sampler due to suction in the downward delivery tube. Fig. 7 does not support an expectation of reduced scatter in the data due to aspiration but Table 2 indicates the difference is significant. Aspiration is probably only justified when the delivery pipe to the sample bottle varies is length and slope.

The passive proportional sampler can be connected to the dam gathering OLF. A receiving bottle of $1 \mathrm{~L}$ capacity or more, as required, can be attached to the outlet of the sampler. The sampler can quantify discharge or additional equipment to measure OLF can be included in the field instrument with the sampler. The assembly of instruments can be used singly or in groups to monitor OLF in small or large areas. Protection for the equipment may be required against livestock and machinery.

\section{CONCLUSION}

Sampler 1 determined parameters for the other two samplers and sampler 2 compared nozzles. This allowed the most appropriate nozzle to be chosen for Sampler 3. The developments with Sampler 3 are described below.

The achievement of samples proportional to discharge means that Sampler 3 with a plastic tube and one to three 
plastic nozzles $0.1 \mathrm{~mm}$ ID within the tube to control sampling rate provides proportional samples of water and no mechanical device is required. Three nozzles are best as they provide the target-sampling rate. This could have a substantial impact on surface water studies worldwide. Loads for any chemical dissolved or suspended in the water can be calculated putting the loss in context with other such losses within a catchment. The sampler uses only difference in water level to initiate and terminate sampling and the components used are inexpensive. The main conclusions are summarized below

(a) Sampler 3 with fine bore inlets $(0.7,1.0$ and $2.0 \mathrm{~mm})$ generates discharge that is proportional to discharge through the Sutro weir.

(b) Sample size down to $0.1 \%$ of total discharge is available from this sampler.

(c) Samples up to 1 liter will be obtained under moderate conditions.

(d) A larger sample will be obtained under very wet conditions

(e) Total discharge can be calculated from sample volume.

(f) Three, two and one nozzle offer sampling rates of $0.11 \%, 0.18 \%$ and $0.24 \%$ of the main discharge. Three nozzles are best as this arrangement satisfies the sampling objectives.

(g) Aspiration of the sampling tube reduced sample size

(h) Aspiration did not affect uniformity of sampling.

(i) Sampler 2 gave sampling rate with different size nozzles.

(j) With sampler 1 ground slope was shown to affect discharge by $10 \%$.

(k) Sample rate is proportional to sampler slope.

(1) Pipe diameter has a large effect on sampling rate.

(m) Outlet location has a small effect on sampling rate.

(n) In one test, sampler characteristics matched those of the $\mathrm{V}$-shaped weir to produce proportional sampling.

(o) The sampler is made from inexpensive plastic and rubber components.

The conclusions listed here satisfy the objectives of a proportional passive sampler gathering samples down to $0.1 \%$ of discharge.

\section{REFERENCES}

Bonta, J.V. and V.C. Goyal. 2000. Comparison of drip flow/low flow measuring devices for infiltrometer runoff measurements. Transactions ASAE 43(6): 1489 - 1498. http://dx.doi.org/10.13031/2013.3048
Clothier, B., S. Green, M. Deurer, A. Mackey, and J. Roygard. 2011. Nutrient leaching losses: from the point, through the farm, to the Catchment. Catchment Science Conference. Dublin 14 - 16 September, 105 pages. ED: G. Shortle, Teagasc, Johnstown Castle, Co. Wexford, Ireland.

Cooksley, S.I., M.I. Stutter, B.O.L. Demars, S. Addy, J. Stochan, \& S.J. Langan, 2011. The Tarland catchment initiative. Catchment Science Conference 2011. Dublin 14 - 16 September, 105 pages. G. Shortle, Teagasc, Johnstown Castle, Co. Wexford, Ireland.

DAFF (Department of Agriculture, Forestry and Fisheries) 2010. Good Agricultural Practice for Protection of Waters, Draft European Communities Regulations, Ireland, 83 pages. Available at: http://www.agriculture.gov.ie/media/migration/farmin gschemesandpayments/crosscompliance/nitrates/Cons ultationPaper090610.pdf . Accessed 30/5/2013.

EPA (2010). Water Quality in Ireland 2007-2009 Ed: McGarrigle, M., J. Lucey, and M. O Cinneide. EPA (Environmental Protection Agency), Johnstown Castle, Wexford, Ireland. 148 pages. Available at: http://www.epa.ie/pubs/reports/water/waterqua/waterq ualityinireland2007-2009.html Accessed 01/08/2013

Franklin, D.H., M.L. Cabrera, J.L. Steiner, D. M. Endale and W. P. Miller. 2001. Evaluation of percent flow captured by a small in-field runoff collector. Transactions ASAE 44(3): 551 - 554.

http://dx.doi.org/10.13031/2013.6115

Harmel, R.D., K.W. King, B.E. Haggard, D.G. Wren and J.M. Sheridan. 2006. Practical guidance for discharge and water quality data collection on small watersheds. Transactions ASABE 49: 937-948.

http://dx.doi.org/10.13031/2013.21745

ILRI. 1978. Discharge measurement structures. Ed: M.G. Bos, P.O. Box 45, 6700 AA Wageningen, The Netherlands, 464 pages.

Malone, R.W., J.V. Bonta, D.R. Lightell. 2003. A low cost composite sampler for drip flow and stream flow. Applied Engineering in Agriculture. 19(1): 59 - 61 . http://dx.doi.org/10.13031/2013.12737

Marechal, D. and I.P. Holman. 2005. Development and application of a soil classification-based conceptual catchment-scale hydrological model. Journal of Hydrology. 12: 277-293.

http://dx.doi.org/10.1016/j.jhydrol.2005.02.018 